Rafał GAŁEK ${ }^{1}$

\title{
NUMERICAL MODELING OF BODY FORCE INDUCED BY CORONA DISCHARGE
}

\begin{abstract}
The paper presents the theoretical basis and results of numerical modeling of corona discharge phenomenon carried out to determine the value of body force that induces the flow of surrounding fluid. The system of two partial differential equations is solved with the values of electric potential $\phi$ and space charge density $\rho_{\mathrm{q}}$ as unknowns. The first equation is of Poisson-type with Laplacian acting on the value of potential and source term dependent on space charge density as well as electric permittivity of the medium. The second equation is current continuity equation, where the current density is composed of charge carrier diffusion term and the term describing their drift in electric field. Particular attention was given to the boundary condition of space charge density due to its indirect nature. Geometry of the problem assumes that positive corona discharge takes place on the sharp edge of the blade-shaped anode while flat grounded plate acts as a cathode. Such configuration enables simplified analysis in 2D Cartesian coordinates assuming that the section plane is sufficiently far from the lateral edges of the blade. The system of equations is solved with MOOSE (Multiphysics Object-Oriented Simulation Environment) Framework released in public domain on GNU LGPL license by Idaho National Laboratory. Presented results include 2D distributions of electric potential, electric field strength, space charge density and body force in air surrounding electrodes.
\end{abstract}

Keywords: ion wind, electrostatic fluid accelerator, EHD flow, finite element method, system of differential equations

\section{Introduction}

Electrostatic Fluid Accelerators (EFA) have recently drawn some attention as a potential alternative to rotary devices mainly in electronic cooling applications. Besides some considerable drawbacks such as a need for very high voltage, the technology has also a substantial advantage: it is able to propel transfer fluid without any moving parts. Instead the momentum is transferred to neutral gas molecules by ions created with corona discharge and accelerated in electric field resulting in an electrohydrodynamic (EHD) fluid flow. The proof that

\footnotetext{
1 Autor do korespondencji/corresponding author: Rafał Gałek, Rzeszow University of Technology, 8 Powstańców Warszawy Ave., 35-959 Rzeszów, tel.: (17) 7432382, e-mail: rafalgalek@prz.edu.pl
} 


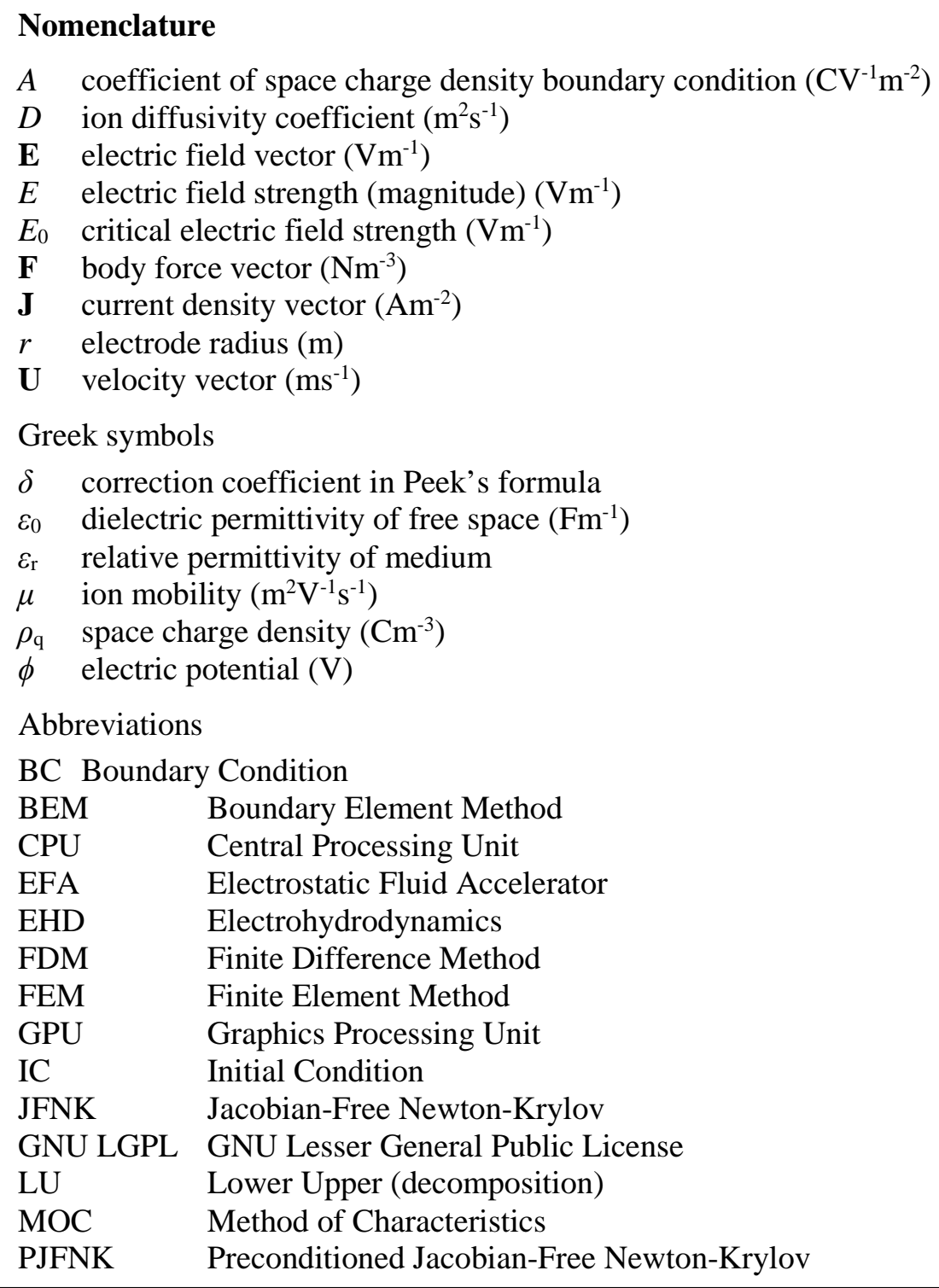

Electrostatic Fluid Accelerator can successfully replace regular rotary fan is presented in [1] where two EHD blowers were fitted into the functional laptop computer. Although the temperatures of CPU and GPU with EHD cooling was found to be approximately $10^{\circ} \mathrm{C}$ higher than those observed with stock rotary fans, it was indicated that internal design of computer was optimized for regular fan and not for an EHD blower. 
The assessment of performance of the Electrostatic Fluid Accelerator usually needs an experimental investigation but it is often beneficial to precede such research with numerical modeling. A number of papers addressed that issue in recent years mainly adopting one of the two approaches. The first is an application of custom numerical codes written specifically for corona discharge phenomenon while the second relies on commercial Finite Element Method (FEM) simulation software.

Among custom codes the Finite Difference Method (FDM) is often preferred due to its simplicity. The solution of corona discharge problem based on FDM is presented in [2]. Since equations are tightly coupled, authors proposed an iterative algorithm implemented in MATLAB to calculate electric potential, current density, fluid pressure and velocity. The Finite Difference Method was also used in [3], however authors reported problems with numerical stability due to high gradients of electric field which required special approach involving ion balance performed on grid cells. In [4] an iterative FDM solution was divided into two stages. The first was performed to find a boundary condition for ion number density on the corona wire while the second one sought the final solution. Problems involving multiple corona electrodes usually require full 3D solution which also can be obtained by Finite Difference Method as demonstrated in [5].

The main drawback of FDM is its inability to account for sharp geometry of corona electrode. In fact a common approximation in this method is to treat a wire or electrode tip as a nodal point which is obviously far from reality. To overcome this problem some more sophisticated algorithms have been developed. In [6] a hybrid approach involving Boundary Element Method (BEM), Finite Element Method and the Method of Characteristics (MOC) is presented. This allows each type of equation to be solved with most effective method: Laplace approximation is solved with BEM, Poisson equation with FEM and charge transport with MOC. The paper also addresses the issue of space charge density boundary condition on the surface of corona electrode which is dependent on the value of electric field strength. In [7] this boundary condition is investigated even further by comparison between direct ionisation criterion and two approximate formulations. Similar FEM-MOC hybrid method is demonstrated in [8], where structured mesh used for MOC is constructed on the basis of electric field lines and equipotential lines and has to be redefined in each iteration. The solution obtained with hybrid method was also used to calculate body force and velocity in [9]. Comparison of simulation results with hot-wire anemometer measurements showed a good agreement except for points close to the axis.

Among commercial FEM software COMSOL Multiphysics seems to be the most popular choice in the field of corona discharge problems. It provides the means to solve Poisson equation with ready-made Electrostatics module while charge transport may be implemented with Coefficient Form PDE or General Form PDE module. The software also has simple interface for coupling the solu- 
tion with Laminar Flow module to calculate velocity field. In [10] and [11] COMSOL Multiphysics was used to solve corona discharge problem in wire-togrid and blade-to-plane geometries respectively. It is important to note that charge transport equation was solved with convection component resulting from fluid movement so the model was fully coupled with Navier-Stokes equations. Combined iterative scheme involving COMSOL Multiphysics and MATLAB was used in [12] where MATLAB algorithm was used to find space charge density boundary condition on the surface of corona electrode. In [13] analysis performed with COMSOL Multiphysics aided development of flow rate sensor using corona discharge phenomenon. Examples of 3D analysis of EHD problem are scarce but not absent. In [14] such problem was solved with COMSOL Multiphysics in pin-to-plane configuration, but unfortunately the details of handling sharp electrode geometry were not clarified. Corona discharge problem with uncommon configuration of electrodes was solved with COMSOL Multiphysics in [15]. In addition to positive and neutral electrodes also a negative electrode was introduced to further accelerate ion produced in ionisation zone.

In present paper a solution of corona discharge problem in 2D blade-toplane geometry is presented. A system of two coupled partial differential equations is solved resulting in electric potential $\phi$ and space charge density $\rho_{\mathrm{q}}$ distributions. Finally, the body force acting on the fluid is calculated. The issue of non-uniform space charge density on the surface of the corona electrode is also addressed. The problem is solved with MOOSE (Multiphysics Object-Oriented Simulation Environment) Framework by Idaho National Laboratory available in public domain on GNU LGPL license.

\section{Problem statement}

\subsection{Governing equations}

Distribution of electric potential $\phi$ is described by Poisson equation known from electrostatics [16]:

$$
\Delta \phi=-\frac{\rho_{\mathrm{q}}}{\varepsilon_{0} \varepsilon_{\mathrm{r}}}
$$

where $\Delta$ is Laplace operator, $\varepsilon_{0}$ is dielectric permittivity of free space and $\varepsilon_{\mathrm{r}}$ is relative permittivity of the medium. Electric field vector may be calculated as:

$$
\mathbf{E}=-\nabla \phi
$$

The second governing equation imposes current continuity:

$$
\nabla \cdot \mathbf{J}=0
$$


where $\mathbf{J}$ is current density. In corona discharge problem it may be expressed as a sum of three components - the term responsible for charge carriers drift in electric field, the convection term and the diffusion term [17]:

$$
\mathbf{J}=\mu \mathbf{E} \rho_{\mathrm{q}}+\mathbf{U} \rho_{\mathrm{q}}-D \nabla \rho_{\mathrm{q}}
$$

where $\mu$ is ion mobility in an electric field, $\mathbf{U}$ is medium velocity vector and $D$ is diffusivity coefficient of ions. As can be seen from (4) calculation of current density requires knowledge about fluid velocity so the coupling to NavierStokes equations is necessary. Nevertheless, vast majority of solution methods developed up to date neglects this coupling on the basis of the fact that ion velocity due to convection is about an order of magnitude smaller than the velocity resulting from a drift in electric field. This assumption simplifies (4) to the form:

$$
\mathbf{J}=\mu \mathbf{E} \rho_{\mathrm{q}}-D \nabla \rho_{\mathrm{q}}
$$

Corona discharge problem, therefore, comes down to solution of equations (1) and (3) with current density given by (5) and appropriate boundary conditions. Relative permittivity of the medium $\varepsilon_{\mathrm{r}}$, ion mobility $\mu$ and diffusivity coefficient of ions $D$ are parameters of the model. Finally, the body force may be calculated as:

$$
\mathbf{F}=\rho_{\mathrm{q}} \mathbf{E}=-\rho_{\mathrm{q}} \nabla \phi
$$

\subsection{Geometry and boundary conditions}

The geometry of the problem under consideration consists of a sharp blade acting as corona electrode and flat plate as a neutral cathode. Electric potential and space charge density distributions at a distance sufficiently far from lateral edges of the blade may be, therefore, approximated by solution in 2D Cartesian coordinates. The blade is $0.6 \mathrm{~mm}$ thick with wedge-shaped contraction towards the edge and $1.65 \mathrm{~mm}$ radius of fillet between flat and wedge sections. The very edge of the blade is modelled as a section of a cylinder with a radius of $50 \mu \mathrm{m}$. The distance from the tip of corona electrode to flat cathode is $5 \mathrm{~mm}$. The axis of the blade is also the axis of symmetry for the whole geometry which means that only half of the domain needs to be modelled. Computational domain is shown in Fig. 1. 

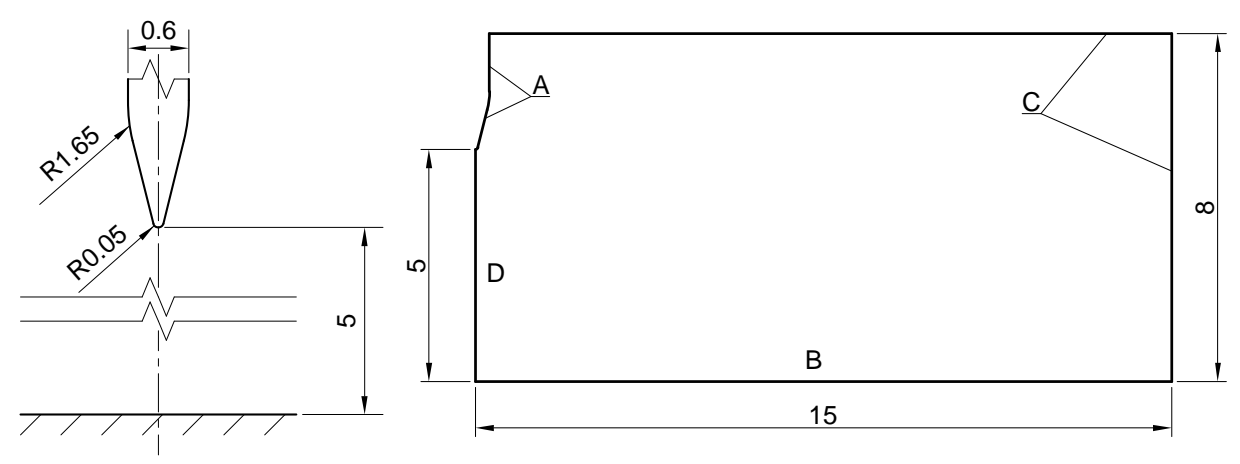

Fig. 1. Geometry of the problem. A - corona electrode, B - cathode, C - free boundaries, $\mathrm{D}-$ axis of symmetry. Dimensions given in $\mathrm{mm}$

The system of equations (1) and (3) needs boundary conditions (BC) for both electric potential and space charge density. On the surface of the electrodes it is straightforward to prescribe Dirichlet type boundary conditions for electric potential. In the problem under consideration potential on the corona electrode was set to $12000 \mathrm{~V}$ while the cathode was grounded. Zero total flux was denoted as BC for potential at remaining part of the boundary (i.e. axis of symmetry and free boundaries). For space charge density zero total flux is assigned on the axis of symmetry and zero diffusive flux on the cathode and free boundaries as suggested for example in [11]. The boundary condition for space charge density on the surface of the corona electrode should act as a charge injection law but there is no generally accepted method to account for this effect. Some authors use an iterative procedure of finding a value of $\rho_{\mathrm{q}}$ on the corona electrode such that the value of electric current calculated with numerical model equals the value measured experimentally. In the absence of experimental data this approach is however unfeasible. Alternative method is based on Kaptzov's assumption which states that with increasing voltage a corona discharge occurs at a point with certain value of electric field but once a discharge is established local $\mathbf{E}$ value remains constant despite of changing voltage. The magnitude of this critical electric field strength $E_{0}$ is often obtained from Peek's formula whose two variants have been derived for highly symmetrical spherical and cylindrical geometries. It is therefore, strictly valid only if electric field is uniform over the surface of corona electrode $[6,18]$. In simple configurations where this condition is observed it is possible to iteratively search for uniform value of space charge density on the surface of corona electrode such that resulting value of electric field strength meets the critical value $E_{0}$ calculated from Peek's formula. However, in general case prescribing uniform value of $\rho_{\mathrm{q}}$ over entire surface of corona electrode must be seen as approximation.

To overcome this problem an alternative form of space charge density boundary condition was proposed in [8]: 


$$
\rho_{\mathrm{q} 0}= \begin{cases}A\left(E-E_{0}\right) & \text { for } E \geq E_{0} \\ 0 & \text { for } E<E_{0}\end{cases}
$$

where $\rho_{\mathrm{q} 0}$ is local value of space charge density on the surface of corona electrode, $E$ is local value of electric field strength, $E_{0}$ is critical value of electric field strength and $A$ is an arbitrary coefficient. Such formulation imposes nonuniform space charge density distribution on the surface of corona electrode in case of non-uniform electric field and ensures that injection of charge takes place only at points where the discharge occurs (i.e. $E>E_{0}$ ). Although such $\mathrm{BC}$ presents significant improvement over the uniform $\rho_{\mathrm{q}}$ formulation, it introduces some new problems. First of them is the fact that equation (7) assumes the coupling between Dirichlet-type BC for space charge density and the solution of potential field which may potentially pose some difficulties for numerical algorithm. The second is the lack of clarity in the matter of proper choice of the value of the coefficient $A$. In [8] authors suggest that this value should be large which is not clear but justified in their case since they solve the non-dimensional form of governing equations.

In present work a slight modification to $\mathrm{BC}$ defined by (7) is proposed. To avoid coupling with Poisson potential solution the local value of $E$ is replaced by the value obtained from precomputed Laplace solution. Such solution calculated simply by setting a right hand side of equation (1) to 0 is fast, robust and may be reached within few seconds. It is important to note that such approach cannot be considered strictly - it is clearly another approximation. Since charge injection generally causes a decrease in the value of local electric field, the Laplace solution gives an estimation of maximum possible area of corona discharge but it is still closer to real physics of the problem than uniform $\rho_{\mathrm{q}}$ approach where corona area must be set arbitrarily.

The issue of the $A$ coefficient from equation (7) is addressed iteratively in present work. Instead of setting its value arbitrarily, the simulation is performed several times with different values of $A$ until the average electric field strength over coronating points on the electrode surface meets the value of $E_{0}$. The critical value $E_{0}$ of electric field for the purposes of iteration scheme as well as for the equation (7) is calculated from Peek's formula for cylindrical geometry [6]:

$$
E_{0}=3.1 \cdot 10^{6} \delta\left(1+\frac{0.308}{\sqrt{\delta r}}\right)
$$

where $E_{0}$ is given in $\mathrm{V} / \mathrm{m}, \delta$ equals 1 for $25^{\circ} \mathrm{C}$ and $101325 \mathrm{~Pa}$ and $r$ is electrode radius given in $\mathrm{cm}$.

It is important to note that in general a corona discharge problem needs an appropriate treatment of two distinct zones of the domain. In immediate vicinity 
of the corona electrode an ionisation zone occurs. The charge carriers are produced there, but the dimension of the zone is negligible compared to the domain size. It is therefore usually neglected in EHD simulations where an injection law accounts for charge production instead. The remaining area is called drift zone due to charge transport phenomena taking place in its volume. Most studies are focused on solving governing equations (1) and (3) in the drift zone only and such approach was adopted in present work.

The complete set of boundary conditions resulting from the above considerations is summarized in Table 1. with boundary names according to Fig. 1.

Table 1. Boundary conditions

\begin{tabular}{|c|l|l|}
\hline Boundary & \multicolumn{1}{|c|}{ Potential BC } & \multicolumn{1}{c|}{ Space charge density BC } \\
\hline \hline A & Dirichlet & charge injection \\
\hline B & Dirichlet & zero diffusive flux \\
\hline C & zero total flux & zero diffusive flux \\
\hline D & zero total flux & zero total flux \\
\hline
\end{tabular}

\section{Solution}

The system of equations (1) and (3) was solved with MOOSE (Multiphysics Object-Oriented Simulation Environment) Framework by Idaho National Laboratory available in public domain on GNU LGPL license [19]. It is an environment developed to efficiently solve coupled systems of nonlinear partial differential equations by means of Jacobian-Free Newton-Krylov (JFNK) methods. MOOSE being fairly high-level software relies heavily on more basic library libMesh developed at University of Texas [20].

MOOSE requires the system of PDEs to be given in a weak form (aka variational statement) which comes down to multiplying equations by test function, integrating them over the domain and applying a divergence theorem. Such treatment results in equations containing both domain and boundary integrals. The former is responsible for physical phenomena taking place in the bulk of the domain and give the basis to formulate MOOSE Kernels while the latter account for boundary conditions. From the user's point of view the main effort is to identify Kernels and BCs required for particular system of equations and assign them to each variable. The software offers an extensive library of Kernels suitable for a wide range of commonly encountered physical mechanisms such as diffusion or convection, although some non-typical cases may require a custom Kernel to be written by user. The same applies to boundary conditions.

Besides Kernels and BCs MOOSE offers many other interfaces called Systems to enable precise control of solution process and to acquire all required data from final solution. As examples one can point an ICs System responsible for initial conditions, a TimeSteppers System controlling the advance through 
time in transient solves or Auxiliary Kernels System used for explicit calculations.

To enable FEM solution the domain was discretized with 165376 elements of 6-node triangular type resulting in 331829 nodes in whole domain. The equations (1) and (3) were reformulated into weak form and required Kernels were identified. It was possible to use ready-made Kernels for diffusion and source terms in Poisson equation as well as diffusion term in charge transport equation but the Kernel for charge drift term had to be additionally implemented. Regarding boundary conditions there was a need to implement charge injection $\mathrm{BC}$ on the basis of considerations presented in section 2 as well as zero diffusive flux BC. Electric field $\mathbf{E}$ and body force $\mathbf{F}$ given by equations (2) and (6) respectively were defined as auxiliary variables due to their explicit dependence on $\phi$ and $\rho_{\mathrm{q}}$ and were being calculated directly during solution process. It was assumed that fluid under consideration is air with relative dielectric permittivity $\varepsilon_{\mathrm{r}}=1$, ion mobility $\mu=2.1 \cdot 10^{-4} \mathrm{~m}^{2} \mathrm{~V}^{-1} \mathrm{~s}^{-1}$ and diffusivity coefficient of ions $D=2.66 \cdot 10^{-5} \mathrm{~m}^{2} \mathrm{~s}^{-1}[11]$.

The solution procedure began with calculation of Laplacian distribution of electric potential from equation (1) with right hand side set to 0 . Subsequently the Laplacian distribution of electric field was obtained and used together with the value of critical electric field $E_{0}$ calculated from Peek's equation to formulate a charge injection boundary condition. The main solution was then started with a guessed value of $A$ coefficient in charge injection BC. The transient solver of Preconditioned Jacobian-Free Newton-Krylov (PJFNK) type was used with Lower-Upper (LU) preconditioner. Adding a time derivative and using a transient solver ensured a smooth start of the solution procedure and allowed gradual evolution towards steady-state with good convergence in each timestep. Steady-state detection implemented by default in MOOSE was used to stop simulation when relative difference in solution variables in subsequent timesteps became smaller than chosen threshold. After reaching the steady-state the average value of electric field over coronating points on the electrode surface was checked and compared with Peek's value. A custom postprocessor was required to calculate the average electric field only from points where Laplacian field has the value greater than $E_{0}$. If the average and critical value of electric field were different, the $A$ coefficient in space charge $\mathrm{BC}$ was corrected and the simulation was performed again. Otherwise the solution procedure could be stopped since all assumptions about charge injection specified in section 2 have been satisfied.

\section{Results and discussion}

The solution of the problem formulated in previous sections are twodimensional distributions of electric potential $\phi$, electric field $\mathbf{E}$, space charge density $\rho_{\mathrm{q}}$ and body force $\mathbf{F}$ presented in Figures 2-6. 


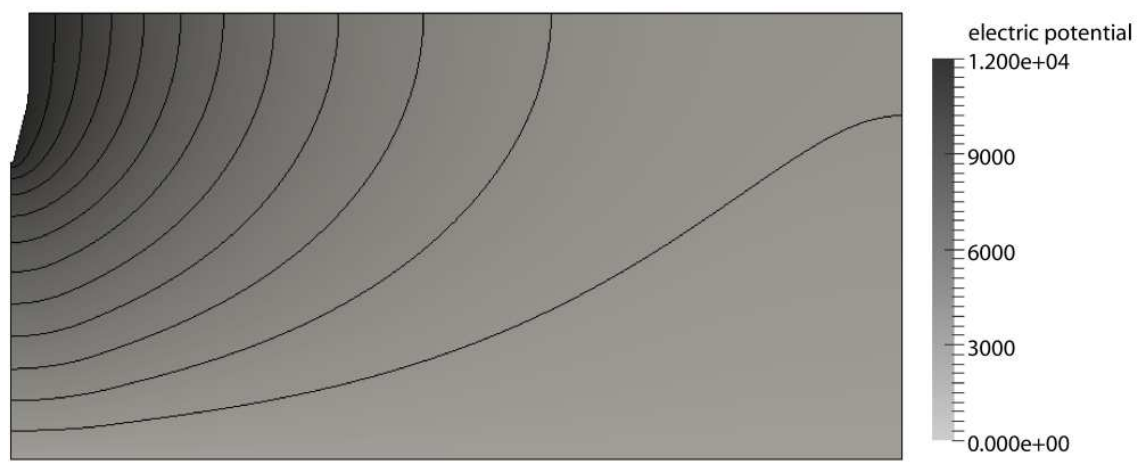

Fig. 2. Distribution of electric potential in $\mathrm{V}$

The distribution of electric potential is very similar to solution obtained for pure electrostatic problem (i.e. Laplacian solution) which suggests that the very existence of space charge does not affect the potential field significantly. This observation generally remains in compliance with an assumption referred to as the Deutsch approximation [21]. The value of electric potential decreases from corona electrode to cathode and outer boundaries in a manner quite typical for a diffusion mechanism. The shape of the potential isolines however indicates that the potential $\mathrm{BC}$ on free boundaries may need some further consideration. There is no apparent physical reason for the lowest isoline to have significantly different shape from other lines. In present work it is clearly caused by zero total flux boundary condition on the right edge of the domain, but the shape of the lowest isoline indicates that some kind of absorption boundary condition would be more appropriate here, as suggested in [11].

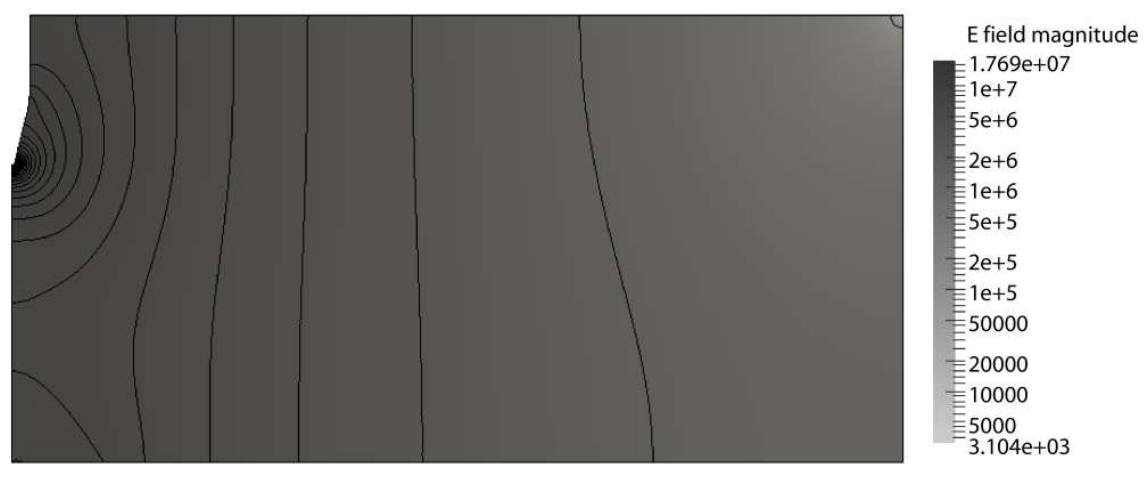

Fig. 3. Distribution of electric field magnitude in $\mathrm{V} / \mathrm{m}$

As might be expected the electric field magnitude has the highest value near the corona electrode tip due to high gradient of electric potential in that re- 
gion. Although it decreases rapidly towards cathode, an interelectrode gap is still the region of relatively high values of electric field which is required to effectively accelerate charge carriers.
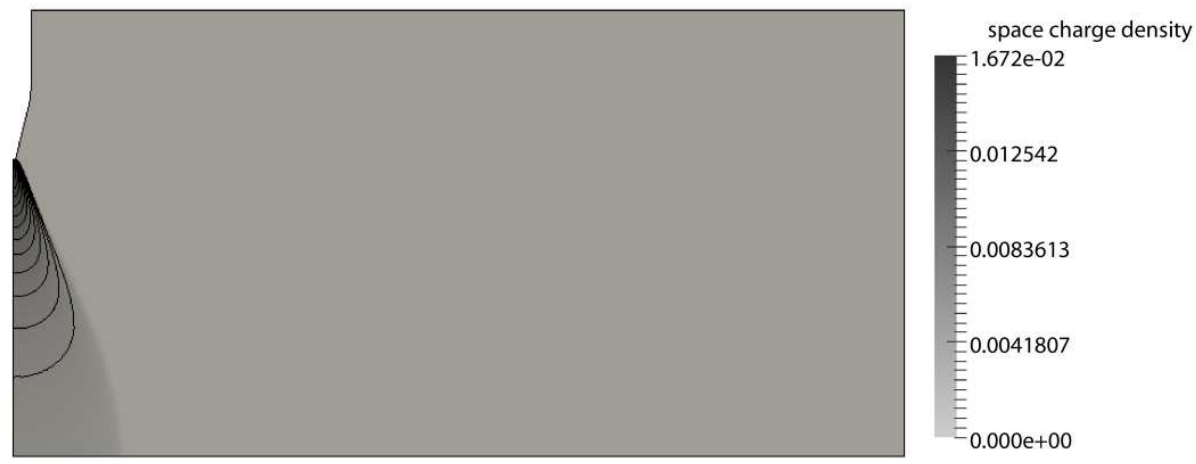

Fig. 4. Distribution of space charge density in $\mathrm{C} / \mathrm{m}^{3}$

The space charge density distribution illustrates the fact that the whole problem is founded on charge injection phenomenon. The ion cloud originates at the very tip of the corona electrode and spans towards cathode due to diffusion and charge drift mechanisms. It is important to note that the boundary of the ion cloud is clearly visible and the space charge density in the rest of the domain is practically 0 . Such distribution suggests that body force may be expected only in the narrow region near the axis where space charge density values are fairly high.

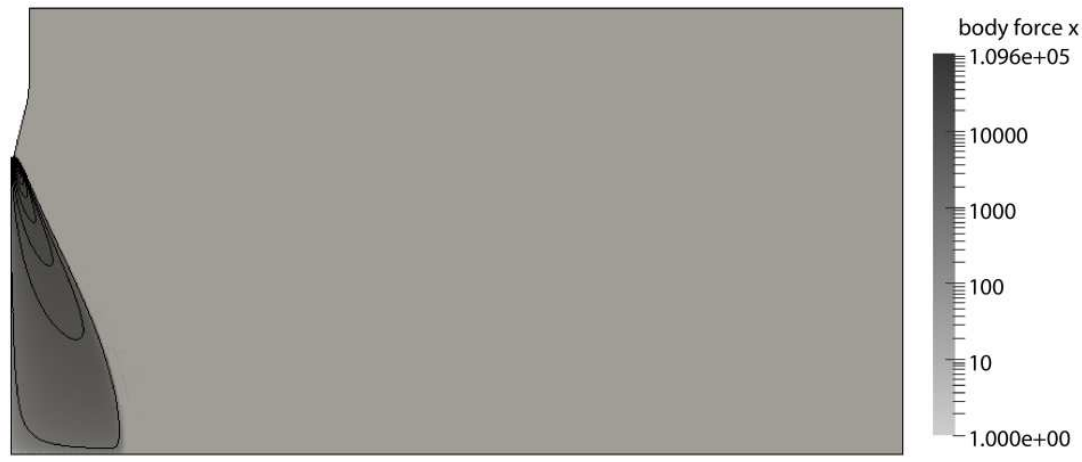

Fig. 5. Distribution of body force $x$ component in $\mathrm{N} / \mathrm{m}^{3}$ ( $\mathrm{x}$ axis pointing right) 


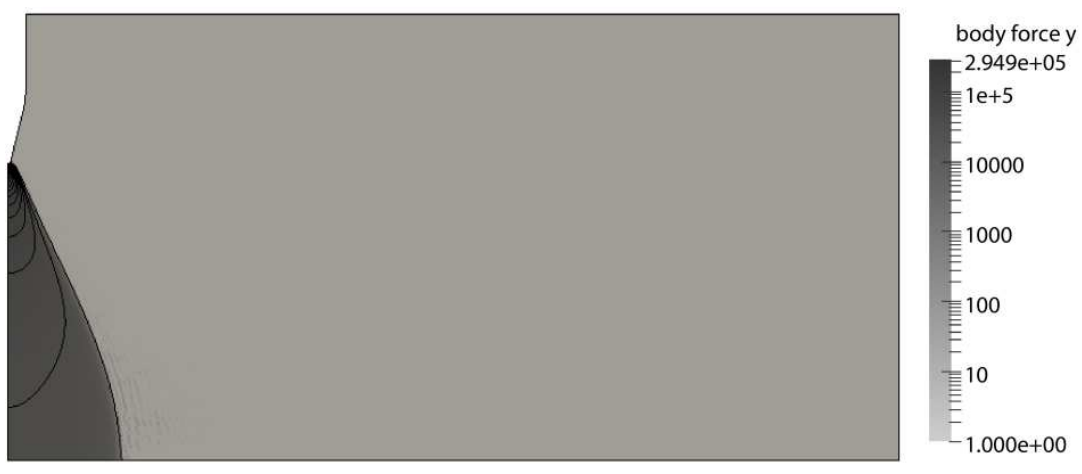

Fig. 6. Distribution of body force y component in $\mathrm{N} / \mathrm{m}^{3}$ (y axis pointing downwards)

Body force $\mathrm{x}$ and $\mathrm{y}$ components shown in Fig. 5. and Fig. 6. respectively have different distributions but both are concentrated in the region restricted by ion cloud. Values of $\mathrm{x}$ component are generally smaller and decrease faster towards cathode than values of y component. A distinct domination of y component is further confirmed by the fact that its distribution differs insignificantly from the distribution of the body force magnitude. It may be predicted that such distribution of body force will result in jet-like flow of the medium towards cathode which would be useful in spot cooling applications where intense heat removal is needed at relatively small area.

\section{Conclusion and future work}

The results of numerical modelling of the body force induced by corona discharge have been presented. The problem has been defined by the system of partial differential equations and solved with a set of appropriate boundary conditions by means of MOOSE Framework. A particular stress has been placed upon the proper formulation of charge injection boundary condition. Obtained results allow to analyze potential, electric field, space charge density and body force distributions related with corona discharge phenomenon.

Future work should use the solution from current study in Navier-Stokes equations to investigate the flow field induced by the body force. It will allow an assessment of potential real-world applications of corona discharge device with given geometry and parameters for spot cooling or similar purposes related with jet flow of the medium.

\section{References}

[1] Jewell-Larsen N.E., Ran H., Zhang Y., Schwiebert M.K., Honer K.A., Mamishev A.V.: Electrohydrodynamic (EHD) cooled laptop, 2009 25th Annual IEEE 
Semiconductor Thermal Measurement and Management Symposium, 261-266, San Jose, March 2009.

[2] Kamboh S.A., Labadin J., Rigit A.R.H.: Computational modeling and simulation of EHD ion-drag pumping using finite difference method, 2013 1st International Conference on Artificial Intelligence, Modelling and Simulation, 207-211, Kota Kinabalu, December 2013.

[3] Gallandat N., Rhett Mayor J.: Novel heat sink design utilizing ionic wind for efficient passive thermal management of grid-scale power routers, Journal of Thermal Science and Engineering Applications, 7 (2015) 31004-1-31004-8.

[4] Komeili B., Chang J., Harvel G.D., Ching C.Y., Brocilo D.: Flow characteristics of wire-rod type electrohydrodynamic gas pump under negative corona operations, Journal of Electrostatics, 66 (2008) 342-353.

[5] Zhang J., Lai F.C.: Effect of emitting electrode number on the performance of EHD gas pump in a rectangular channel, Journal of Electrostatics, 69 (2011) 486-493.

[6] Adamiak K., Atten P.: Simulation of corona discharge in point-plane configuration, Journal of Electrostatics, 61 (2004) 85-98.

[7] Adamiak K., Atrazhev V., Atten P.: Corona discharge in the hyperbolic point-plane configuration: Direct ionization criterion versus approximate formulations, IEEE Transactions on Dielectrics and Electrical Insulation, 12 (2005) 1025-1033.

[8] Khaddour B., Atten P., Coulomb J.-L.: Electrical field modified by injected space charge in blade-plate configuration, IEEE Transactions on Magnetics, 42 (2006) 651-654.

[9] Zhao L., Adamiak K.: EHD flow in air produced by electric corona discharge in pin-plate configuration, Journal of Electrostatics, 63 (2005) 337-350.

[10] Jewell-Larsen N.E., Karpov S.V, Krichtafovitch I.A., Jayanty V., Hsu C.-P., Mamishev A.V.: Modeling of corona-induced electrohydrodynamic flow with COMSOL multiphysics, Proc. ESA Annual Meeting on Electrostatics, Paper E1, 1-13, Minneapolis, June 2008.

[11] Jewell-Larsen N.E., Zhang P.Q., Hsu C.-P., Krichtafovitch I.A., Mamishev A.V.: Coupled-physics modeling of electrostatic fluid accelerators for forced convection cooling, $9^{\text {th }}$ AIAA/ASME Joint Thermophysics and Heat Transfer Conference, 1-10, San Francisco, June 2006.

[12] Ahmedou O., Havet M.: Effect of process parameters on the EHD airflow, Journal of Electrostatics, 67 (2009) 222-227.

[13] Quast M., Lalic N.R.: Measuring and calculation of positive corona currents using COMSOL Multiphysics ${ }^{\circledR}$, Proceedings of the COMSOL Conference, 1-7, Milan 2009.

[14] Zhang J., Zhao C., Li H., Tao W.: 3D numerical simulation of heat transfer of a heated plate under the electric field generated by a needle electrode, Mathematical Problems in Engineering, 2014, 1-10.

[15] Martins A.A.: Simulation of a wire-cylinder-plate positive corona discharge in nitrogen gas at atmospheric pressure, Physics of Plasmas, 19 (2012) 1-11.

[16] Jackson J.D.: Classical Electrodynamics, $3^{\text {rd }}$ ed., Wiley, New York 1999. 
[17] Castellanos A.: Electrohydrodynamics, Springer-Verlag Wien GmbH, New York 1998.

[18] Tirumala R., Go D.B.: Comparative study of corona discharge simulation techniques for electrode configurations inducing non-uniform electric fields, Journal of Electrostatics, 72 (2014) 99-106.

[19] Gaston D., Newman C., Hansen G., Lebrun-Grandié D.: MOOSE: A parallel computational framework for coupled systems of nonlinear equations, Nuclear Engineering and Design, 239 (2009) 1768-1778.

[20] Kirk B.S., Peterson J.W., Stogner R.H., Carey G.F.: libMesh: a C++ library for parallel adaptive mesh refinement/coarsening simulations, Engineering with Computers, 22 (2006) 237-254.

[21] Bouziane A., Hidaka K., Taplamacioglu M.C., Waters R.T.: Assessment of corona models based on the Deutsch approximation, Journal of Physics D: Applied Physics, 27 (1994) 320-329.

\section{MODELOWANIE NUMERYCZNE SIEY MASOWEJ GENEROWANEJ PRZEZ WYLADOWANIE KORONOWE}

\section{Streszczenie}

Artykuł prezentuje podstawy teoretyczne oraz wyniki modelowania numerycznego zjawiska wyładowania koronowego w celu wyznaczenia wartości siły masowej wymuszającej przepływ medium, w którym to wyładowanie zachodzi. Rozwiązywany jest układ dwóch równań różniczkowych cząstkowych, gdzie niewiadomymi są wartości potencjału elektrycznego $\phi$ oraz gęstości przestrzennej ładunku $\rho_{\mathrm{q}}$. Pierwsze $\mathrm{z}$ równań ma postać równania Poissona z laplasjanem operującym na wartości potencjału oraz członem źródła zależnym od gęstości przestrzennej ładunku i przenikalności elektrycznej ośrodka. Drugie z równań to równanie ciągłości prądu, gdzie jako składniki gęstości prądu elektrycznego uwzględniono człon odpowiedzialny za dyfuzję nośników ładunku oraz człon opisujący ich dryf w polu elektrycznym. Szczególną uwagę zwrócono na warunek brzegowy przestrzennej gęstości ładunku ze względu na jego pośredni charakter. Geometria problemu zakłada, że wyładowanie koronowe zachodzi na anodzie w kształcie ostrza, podczas gdy katodę stanowi uziemiona płaska płytka. Taka geometria pozwala na uproszczenie analizy do przypadku rozpatrywanego w dwuwymiarowych współrzędnych kartezjańskich przy założeniu, że płaszczyzna przekroju znajduje się odpowiednio daleko od bocznych krawędzi ostrza. Do rozwiązania układu równań wykorzystano środowisko MOOSE (Multiphysics Object-Oriented Simulation Environment) Framework udostępnione w domenie publicznej na licencji GNU LGPL przez Idaho National Laboratory. Przedstawione wyniki obejmują dwuwymiarowe rozkłady wartości potencjału i pola elektrycznego, gęstości przestrzennej ładunku oraz siły masowej w medium otaczającym elektrody.

Słowa kluczowe: wiatr jonowy, elektrostatyczny akcelerator płynu, przepływ elektrohydrodynamiczny, metoda elementów skończonych, układ równań różniczkowych

DOI: $10.7862 / \mathrm{rm} .2017 .14$

Otrzymano/received: 31.03 .2017

Zaakceptowano/accepted: 14.05.2017 